\title{
Chromobacterium aquaticum sp. nov., isolated from spring water samples
}

\author{
Chiu-Chung Young, ${ }^{1}$ A. B. Arun, ${ }^{1}$ Wei-An Lai, ${ }^{1}$ Wen-Ming Chen, ${ }^{2}$ \\ Jiu-Hsing Chao, ${ }^{1}$ Fo-Ting Shen, ${ }^{1}$ P. D. Rekha ${ }^{1}$ and Peter Kämpfer ${ }^{3}$ \\ ${ }^{1}$ College of Agriculture and Natural Resources, Department of Soil and Environmental Sciences, \\ National Chung Hsing University, Taichung 402, Taiwan, ROC \\ ${ }^{2}$ Laboratory of Microbiology, Department of Seafood Science, National Kaohsiung Marine \\ University, Kaohsiung City 811, Taiwan, ROC \\ ${ }^{3}$ Institut für Angewandte Mikrobiologie, Universität Giessen, Giessen, Germany
}

Correspondence

Peter Kämpfer peter.kaempfer@humwelt. uni-giessen.de
During the characterization of micro-organisms from spring-water samples collected from Yang-Ming Mountain, Taipei County, Taiwan, strain CC-SEYA- $1^{\mathrm{T}}$ was isolated and maintained on nutrient agar (HI-MEDIA) after incubation at $32{ }^{\circ} \mathrm{C}$ for $48 \mathrm{~h}$. Subcultivation was done on nutrient agar at $30{ }^{\circ} \mathrm{C}$ for $2-3$ days. On this medium, CC-SEYA- $1^{\mathrm{T}}$ was able to grow at $25-40{ }^{\circ} \mathrm{C}$, but not at 45 or $15{ }^{\circ} \mathrm{C}$. The organism was also able to grow on tryptone soy agar (HI-MEDIA), R2A agar (Oxoid) and MacConkey agar. The $\mathrm{pH}$ range for growth was determined by measuring the optical density at $595 \mathrm{~nm}$ of cultures grown in nutrient broth (Difco) which was adjusted prior to sterilization to various $\mathrm{pH}$ values $(\mathrm{pH} 3-11$ at intervals of $0.5 \mathrm{pH}$ units) using appropriate biological buffers (Chung et al., 1995). Growth at different temperatures $\left(10-50{ }^{\circ} \mathrm{C}\right)$ was measured in nutrient broth. Growth under anaerobic conditions was determined after incubation in nutrient broth in an Oxoid AnaeroGen system. Growth was recorded by measuring the optical density at $595 \mathrm{~nm}$ of the culture.

Cell morphology was observed under a Zeiss light microscope at $\times 1000$ magnification using cells that had been grown for 3 days at $30{ }^{\circ} \mathrm{C}$ on nutrient agar (Oxoid). Gram-staining was performed as described by Gerhardt

The GenBank/EMBL/DDBJ accession number for the 16S rRNA gene sequence of CC-SEYA- $1^{\top}$ is EU109734. et al. (1994). Poly- $\beta$-hydroxybutyrate granule accumulation was observed by light microscopy after staining the cells with Sudan black.

TBAB (Difco) with 5\% sheep blood was used for haemolysis testing; a clear or semi-clear zone around the colony indicated a positive test. Modified egg yolk agar (Difco) was used for testing lecithinase, lipase and proteolytic activity. Phenotypic characteristics, biochemical tests, carbon source utilization (Biolog-GN2), API ZYM enzyme profiles (bioMérieux), and API 20E (bioMérieux) and API 20NE (bioMérieux) profiles were investigated. Additionally, antibiotic susceptibility testing was carried out using ATB STAPH 5 strips (bioMérieux), according to the manufacturer's recommendations. Fluorescence was tested after plating on King's B medium after $48 \mathrm{~h}$.

Results of morphological and physiological characterization are given in the species description and in Table 1. Strain CC-SEYA- ${ }^{\mathrm{T}}$ was non-fluorescent and was capable of producing acid from various carbohydrates. Carbon substrate utilization tests with organic acids as substrates showed several positive results. In the API 20E (bioMérieux) test, CC-SEYA $-1^{\mathrm{T}}$ was positive for arginine dihydrolase, citrate utilization, gelatinase, glucose oxidation and nitrate reduction, while in the API 20NE test, CC-SEYA- $1^{\mathrm{T}}$ was positive for reduction of nitrate to nitrite, glucose fermentation, arginine dihydrolase, aesculin hydrolysis, gelatinase, and assimilation of glucose, $\mathrm{N}$-acetylglucosamine, potassium 
Table 1. Some genotypic, phenotypic and nutritional characteristics that distinguish strain CC-SEYA-1 ${ }^{\top}$ from other members of the genera Chromobacterium and Aquitalea

Taxa: 1, CC-SEYA-1 ${ }^{\mathrm{T}} ; 2$, C. violaceum ATCC $12472^{\mathrm{T}}$ (Biolog-GN2 data were obtained in this study for these two strains; all other data were obtained from Lau et al., 2006); 3, C. subtsugae DSM $17043^{\mathrm{T}}$ (Biolog-GN2 data were obtained in this study; all other data were obtained from: Martin et al., 2007); 4, Aquitalea magnusonii ATCC BAA- $1216^{\mathrm{T}}$ (all the data were obtained from Lau et al., 2006). -, Not detected.

\begin{tabular}{|c|c|c|c|c|}
\hline Characteristic & 1 & 2 & 3 & 4 \\
\hline Colony colour & Tan & Violet & Violet & Tan \\
\hline DNA G $+C$ content $(\mathrm{mol} \%)$ & 62.3 & 64 & 64.5 & 59.2 \\
\hline Isolation source & Spring water & Soil/water ${ }^{*}$ & Soil & Humic lake \\
\hline Catalase & - & + & + & + \\
\hline Aesculin hydrolysis & + & - & - & - \\
\hline Fermentation of ribose & - & + & - & - \\
\hline Indole production & - & - & - & + \\
\hline Gelatinase & + & + & - & - \\
\hline $3 \%(w / v) \mathrm{NaCl}$ & + & - & - & - \\
\hline \multicolumn{5}{|l|}{ Assimilation of (Biolog-GN2): } \\
\hline$\alpha$-D-Glucose 1-phosphate & + & + & + & - \\
\hline 2,3-Butanediol & + & + & - & - \\
\hline 2-Aminoethanol & + & + & - & - \\
\hline DL- $\alpha$-Glycerol phosphate & + & + & - & - \\
\hline D-Glucose 6-phosphate & + & + & + & - \\
\hline D-Mannose & + & + & - & - \\
\hline D-Serine & + & + & + & - \\
\hline Trehalose & + & + & + & - \\
\hline Inosine & + & + & + & - \\
\hline L-Alaninamide & + & + & - & - \\
\hline L-Phenylalanine & + & + & - & - \\
\hline L-Threonine & + & + & + & - \\
\hline Thymidine & + & + & - & - \\
\hline Uridine & + & + & - & - \\
\hline$\gamma$-Aminobutyric acid & + & - & - & + \\
\hline p-Hydroxyphenylacetic acid & + & - & - & + \\
\hline$\alpha$-Ketoglutaric acid & + & - & - & + \\
\hline cis-Aconitic acid & + & - & - & + \\
\hline Citric acid & + & - & - & + \\
\hline L-Leucine & + & - & + & + \\
\hline
\end{tabular}

${ }^{\star}$ From Gillis \& Logan (2005).

gluconate, capric acid, malic acid, trisodium citrate and phenylacetic acid. In API-ZYM enzyme profiling, CC-SEYA$1^{\mathrm{T}}$ was positive for alkaline and acid phosphatase, butyrate esterase, caprylate esterase (C8), myristate lipase (C14), leucine arylamidase, $\alpha$-chymotrypsin, naphthol-AS-B-1phosphohydrolase and $N$-acetyl- $\beta$-glucosaminidase.

The 16S rRNA gene was analysed as described by Young et al. (2005). Analysis of the sequence data was performed by using the software package MEGA (Molecular Evolutionary Genetics Analysis), version 2.1 (Kumar et al., 2001), after multiple alignments of the data by CLUSTAL_X (Thompson et al., 1997). A distance matrix method (distance options according to the Kimura two-parameter model), including clustering by neighbour-joining (Fig. 1), and a discrete character-based maximum-parsimony method, were used. In each case bootstrap values were calculated based on 1000 replications. The 16S rRNA gene sequence of strain CCSEYA- $1^{\mathrm{T}}$ was a continuous stretch of $1476 \mathrm{bp}$. Sequence similarity calculations indicated that strain CC-SEYA-1 ${ }^{\mathrm{T}}$ showed the greatest degree of similarity to Chromobacterium violaceum (96.8\%) (GenBank accession no. M22510), Chromobacterium subtsugae (96.5\%) (AY344056) and Aquitalea magnusonii (95.8\%) (DQ018117). Lower sequence similarities $(<94.0 \%)$ were found with all other genera shown in Fig. 1 in the family Neisseriaceae.

For $\mathrm{G}+\mathrm{C}$ content calculations, a DNA sample was prepared and degraded enzymically into nucleosides as described by Mesbah et al. (1989). The obtained nucleoside mixture was then separated by HPLC. The G $+\mathrm{C}$ content of strain CC-SEYA- $1^{\mathrm{T}}$ was $62.31 \mathrm{~mol} \%$. DNA-DNA hybridization experiments were performed with the type strain of C. violaceum NCTC $9757^{\mathrm{T}}$ and C. subtsugae DSM 


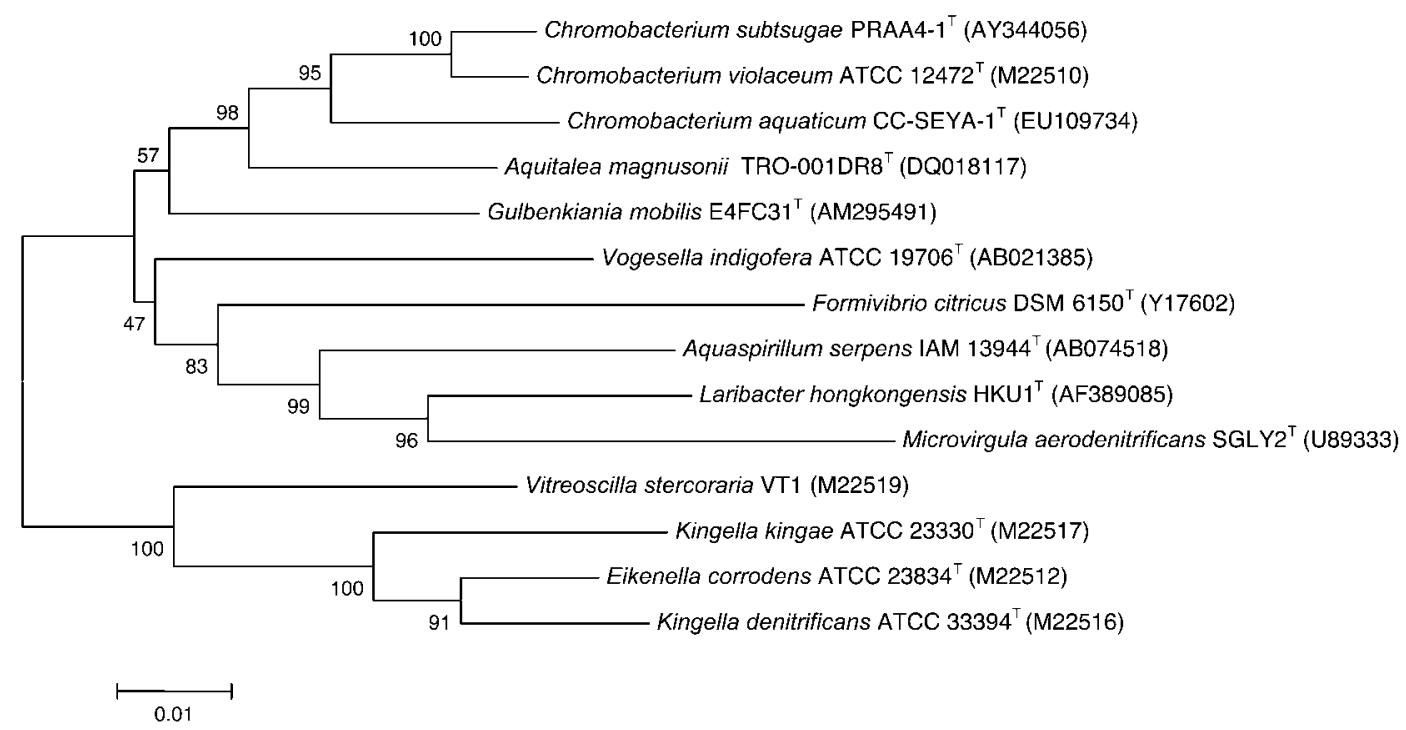

Fig. 1. Phylogenetic analysis based on $16 \mathrm{~S}$ rRNA gene sequences available from the EMBL database (accession numbers are given in parentheses) constructed after multiple alignments of the data by CLUSTAL_X (Thompson et al., 1997). Distances (distance options according to the Kimura two-parameter model) and clustering with the neighbour-joining method was performed by using the software package MEGA version 2.1 (Kumar et al., 2001). Bootstrap values based on 1000 replications are listed as percentages at the branching points. Bar, 0.01 substitutions per nucleotide position.

$10743^{\mathrm{T}}$ using the method described by Ziemke et al. (1998), except that for nick translation, $2 \mu \mathrm{g}$ DNA was labelled during a $3 \mathrm{~h}$ incubation at $15{ }^{\circ} \mathrm{C}$. Strain CC-SEYA- $1^{\mathrm{T}}$ showed relatively low DNA-DNA similarities to C. violaceum NCTC $9757^{\mathrm{T}}$ (37\%, reciprocal analysis $\left.49 \%\right)$ and C. subtsugae DSM $10743^{\mathrm{T}}$ (38\%, reciprocal analysis $44 \%$ ).

Fatty acid methyl esters were prepared, separated and identified according to the instructions of the Microbial Identification System (MIDI; Microbial ID). The fatty acid profile of strain CC-SEYA- ${ }^{\mathrm{T}}$ (given in the species description) was similar to those given for Chromobacterium and Aquitalea species, but also showed some differences (Table 2).

From the sequence analysis of the 16S rRNA gene, it is obvious that the isolate belongs to the genus Chromobacterium. A moderate relationship to Aquitalea is also clear (Fig. 1, Tables 1 and 2). It should be mentioned here, that non-pigmented isolates of $C$. violaceum are well known (Gillis \& Logan, 2005). In our opinion, the differences in phenotype do not justify the proposal of a novel genus, separate from Chromobacterium. Hence, on basis of our results, we propose that strain CC-SEYA- $1^{\mathrm{T}}$ warrants status as a new member of the genus Chromobacterium for which the name Chromobacterium aquaticum sp. nov. is proposed.

\section{Description of Chromobacterium aquaticum sp. nov.}

Chromobacterium aquaticum (a.qua'ti.cum. L. neut. adj. aquaticum living, growing, or found in or by water).
Cells are Gram-negative, aerobic, rod-shaped $(0.3-0.5 \mu \mathrm{m}$ long and 1.5-2 $\mu \mathrm{m}$ wide) and motile by means of a single polar flagellum. Good growth occurs after $48 \mathrm{~h}$ incubation on tryptone soy agar and nutrient agar at $32{ }^{\circ} \mathrm{C}$. Colonies on complex standard medium at $32{ }^{\circ} \mathrm{C}$ are tan-coloured, smooth, shiny and convex with a spreading edge, 1.0$2.0 \mathrm{~mm}$ in diameter and are non-fluorescent. No violet coloured pigmentation. Positive for haemolytic activity ( $5 \%$ sheep blood), lecithinase and lipase production. The

Table 2. Major fatty acid compositions (\%) of the genera Chromobacterium and Aquitalea

Taxa: 1, CC-SEYA-1 ${ }^{\mathrm{T}} ; 2$, C. violaceum ATCC $12472^{\mathrm{T}}$; 3, C. subtsugae DSM $17043^{\mathrm{T}}$ (data from Martin et al., 2007); 4, A. magnusonii ATCC BAA- $1216^{\mathrm{T}}$ (Lau et al., 2006).

\begin{tabular}{|lcccc|}
\hline Fatty acid & $\mathbf{1}$ & $\mathbf{2}$ & $\mathbf{3}$ & $\mathbf{4}$ \\
\hline $\mathrm{C}_{10: 0} 3-\mathrm{OH}$ & 4.6 & 5.2 & 4.3 & 1.5 \\
$\mathrm{C}_{12: 0}$ & 8.8 & 5.6 & 4.9 & 5.1 \\
$\mathrm{C}_{12: 0} 2-\mathrm{OH}$ & 0.2 & 3.0 & 2.8 & 0.0 \\
$\mathrm{C}_{12: 0} 3-\mathrm{OH}$ & 4.4 & 5.0 & 3.9 & 1.2 \\
$\mathrm{C}_{14: 0}$ & 2.6 & 1.7 & 3.2 & 2.8 \\
$\mathrm{C}_{15: 0}$ & 0.6 & - & 1.2 & 2.0 \\
$\mathrm{C}_{16: 1} \omega 7 c+\mathrm{C}_{16: 1} \omega 7 c 2-\mathrm{OH}$ iso $^{*}$ & 33.4 & 35.8 & 41.9 & 52.5 \\
$\mathrm{C}_{16: 0}$ & 25.8 & 23.9 & 24.9 & 21.7 \\
$\mathrm{C}_{17: 0}$ cyclo & - & 1.7 & - & - \\
$\mathrm{C}_{17: 1} \omega 6 c$ & - & - & - & 1.2 \\
$\mathrm{C}_{18: 1} \omega 7 c$ & 18.8 & 15.0 & 10.6 & 8.0 \\
\hline
\end{tabular}

${ }^{*}$ These fatty acids cannot be separated by the MIDI system. 
optimal temperature for growth is $32{ }^{\circ} \mathrm{C}$. The optimal $\mathrm{pH}$ for growth is 6.0; growth occurs at $\mathrm{pH} 5$ and 9.5, but not at $\mathrm{pH} 4.0$ and 10. Growth occurs in the presence of $0-3.5 \%$ $(\mathrm{w} / \mathrm{v}) \mathrm{NaCl}$; optimal growth occurs in the presence of 0 $0.1 \%(\mathrm{w} / \mathrm{v}) \mathrm{NaCl}$. No anaerobic growth on plain nutrient agar or tryptone soy agar supplemented with nitrate was observed. No poly- $\beta$-hydroxybutyrate granule accumulation. Shows aerobic metabolism. Oxidase-, gelatinase- and aesculin-positive, catalase-negative. Nitrate is reduced to nitrite. The fatty acid profile of strain CC-SEYA- $1^{\mathrm{T}}$ is shown in Table 2. Dextrin, glycogen, Tween 40, Tween 80, $N$-acetyl-D-glucosamine, i-erythritol (weak), cellobiose, Dfructose, $\alpha$-D-glucose, $m$-inositol, D-mannose, D-psicose, $\beta$ methyl-D-glucoside (weak), trehalose, turanose, pyruvic acid methyl ester, succinic acid monomethyl ester, acetic acid, cis-aconitic acid, formic acid, D-galacturonic acid, Dgluconic acid, D-glucosaminic acid (weak), $\alpha$-hydroxybutyric acid, $\beta$-hydroxybutyric acid, $p$-hydroxyphenylacetic acid, itaconic acid, $\alpha$-ketobutyric acid, $\alpha$-ketoglutaric acid, $\alpha$-ketovaleric acid (weak), DL-lactic acid, propionic acid, succinic acid, bromosuccinic acid, succinamic acid, L-alaninamide, D-alanine, L-alanine, L-alanyl glycine, Lasparagine, L-aspartic acid, L-glutamic acid, glycyl-Lglutamic acid, L-histidine, hydroxy-L-proline, L-leucine, L-ornithine, L-phenylalanine, L-proline, L-pyroglutamic acid, D-serine, L-serine, L-threonine, DL-carnitine (weak), urocanic acid, inosine, uridine, thymidine, phenylethylamine (weak), 2-aminoethanol, 2,3-butanediol, DL- $\alpha$-glycerol phosphate, $\alpha$-D-glucose 6-phosphate and D-glucose 6-phosphate were utilized (Biolog GN-II). $\alpha$-Cyclodextrin, $N$-acetyl-D-galactosamine, adonitol, D-arabitol, L-fucose, D-galactose, gentiobiose, L-arabinose, DL-lactose, lactulose, maltose, D-mannitol, melibiose, raffinose, L-rhamnose, Dsorbitol, sucrose, xylitol, D-galactonic acid lactone, Dglucuronic acid, $\gamma$-hydroxybutyric acid, malonic acid, quinic acid, D-saccharic acid, sebacic acid, glucuronamide, $\gamma$-aminobutyric acid and glycerol were not utilized as carbon sources (Biolog GN-II). Positive (API 20E and 20NE) for arginine dihydrolase, citrate utilization, gelatinase, glucose oxidation, reduction of nitrate to nitrite, glucose fermentation, aesculin hydrolysis, gelatinase, assimilation of glucose, $\mathrm{N}$-acetylglucosamine, potassium gluconate, capric acid, malic acid, trisodium citrate and phenylacetic acid, but negative for $\beta$-galactosidase, lysine decarboxylase, $\mathrm{H}_{2} \mathrm{~S}$ production, urease, tryptophan deaminase, indole production, acetoin production, mannitol oxidation, inositol oxidation, sorbitol oxidation, rhamnose oxidation, sucrose oxidation, melibiose, amygdalin oxidation, arabinose oxidation, arabinose assimilation, mannose assimilation, mannitol assimilation, maltose assimilation and adipic acid assimilation. Positive for alkaline and acid phosphatase, butyrate esterase (C4), caprylate esterase (C8), myristate lipase (C14), leucine arylamidase, $\alpha$ chymotrypsin, naphthol-AS-B-1-phosphohydrolase and $N$-acetyl- $\beta$-glucosaminidase, but negative for valine arylamidase, cystine arylamidase, trypsin, $\alpha$-galactosidase, $\beta$-galactosidase, $\beta$-glucuronidase, $\alpha$-glucosidase, $\beta$-glucosidase, $\alpha$-mannosidase and $\alpha$-fucosidase in API ZYM enzyme reactions. Sensitive to cotrimoxazole, tetracycline, minocycline, nor/quinolones $2 \mathrm{G}$, levofloxacin and nitrofurantonin; resistant to penicillin, gentamicin, erythromycin, clindamycin, vancomycin, teicoplanin, rifampicin, fusidic acid, quinupristine-dalfo, coagoxacillin and oxacillin. Further physiological features are given in Table 1.

The type strain, isolated from spring-water samples from Yang-Ming Mountain, Taipei County, Taiwan, is CCSEYA- ${ }^{\mathrm{T}}\left(=\right.$ CCUG $55175^{\mathrm{T}}=$ BCRC $\left.17769^{\mathrm{T}}\right)$.

\section{ACKNOWLEDGEMENTS}

This research was kindly supported by a grant from the National Science Council, Taiwan, and Council of Agriculture, EY, Taiwan. We thank W. S. Huang for technical assistance and Professor Duane Bartholomew, Dept of Natural Resources and Environmental Management, University of Hawaii, for help during sample collection. The authors gratefully acknowledge Dr Phyllis A. W. Martin, Insect Biocontrol Laboratory, US Department of Agriculture, Agriculture Research Service, 10300 Baltimore Ave, Beltsville, MD, USA, for providing the type strain of Chromobacterium subtsugae for comparison.

\section{REFERENCES}

Chung, Y. C., Kobayashi, T., Kanai, H., Akiba, T. \& Kudo, T. (1995). Purification and properties of extracellular amylase from the hyperthermophilic archeon Thermococccus profundus DT5432. Appl Environ Microbiol 61, 1502-1506.

Gerhardt, P., Murray, R. G. E., Wood, W. A. \& Krieg, N. R. (editors) (1994). Methods for General and Molecular Bacteriology. Washington, DC: American Society for Microbiology.

Gillis, M. \& Logan, N. A. (2005). Genus IV. Chromobacterium Bergonzini 1881, $153^{\mathrm{AL}}$. In Bergey's Manual of Systematic Bacteriology, vol. 2, pp. 824-827. Edited by D. J. Brenner, N. R. Krieg \& J. T. Staley. New York: Springer.

Kumar, S., Tamura, K., Jakobsen, I. B. \& Nei, M. (2001). MEGA2: Molecular Evolutionary Genetics Analysis software. Bioinformatics 17, 1244-1245.

Lau, H.-T., Faryna, J. \& Triplett, E. W. (2006). Aquitalea magnusonii gen. nov., sp. nov., a novel Gram-negative bacterium isolated from a humic lake. Int J Syst Evol Microbiol 56, 867-871.

Martin, P. A. W., Gundersen-Rindal, D., Blackburn, M. \& Buyer, J. (2007). Chromobacterium subtsugae sp. nov., a betaproteobacterium toxic to Colorado potato beetle and other insect pests. Int J Syst Evol Microbiol 57, 993-999.

Mesbah, M., Premachandran, U. \& Whitman, W. B. (1989). Precise measurement of the $\mathrm{G}+\mathrm{C}$ content of deoxyribonucleic acid by highperformance liquid chromatography. Int J Syst Bacteriol 39, 159-167.

Thompson, J. D., Gibson, T. J., Plewniak, F., Jeanmougin, F. \& Higgins, D. G. (1997). The CLUSTAL_X windows interface: flexible strategies for multiple sequence alignment aided by quality analysis tools. Nucleic Acids Res 25, 4876-4882.

Young, C.-C., Kämpfer, P., Shen, F.-T., Lai, W.-A. \& Arun, A. B. (2005). Chryseobacterium formosense sp. nov., isolated from the rhizosphere of Lactuca sativa L. (garden lettuce). Int J Syst Evol Microbiol 55, 423-426.

Ziemke, F., Höfle, M. G., Lalucat, J. \& Rosselló-Mora, R. (1998). Reclassification of Shewanella putrefaciens Owen's genomic group II as Shewanella baltica sp. nov. Int J Syst Bacteriol 48, 179-186. 